\title{
Association of socioeconomic risk factors with under 5-year mortality in Zabol, Iran, during 2011-2015
}

\author{
Masoud Nakhzari-Moghaddam¹, Parvin Yavari*2, ${ }^{3}$, Alireza Abadi², 3 , Narges Rostami-Gooran ${ }^{4}$ \\ Received: 21 Feb 2018 \\ Published: 26 Jun 2019
}

\begin{abstract}
Background: Under-5 mortality is an important health indicator of a country's development and every country is committed to decrease it. Children under-5 years are vulnerable to the imbalance of socioeconomic inequality and are dependent on the adults to remain healthy. The aim of this study was to determine the association of socioeconomic factors with under-5 mortality in Zabol.

Methods: This descriptive cross sectional study was performed on 2001 children younger than 5 years who were under the coverage of Zabol University of Medical Sciences between 2011 and 2015. The data were collected using standard questionnaires on mortality of infant and children 1-59 months old, questionnaires determining socioeconomic condition, and health center data files. The analyses were performed using SPSS software version 21, and significance level was set at 0.05 for all tests.

Results: The most common causes of death under 5 years of age included immaturity, congenital defects, and respiratory diseases. In the logistic regression model, father's addiction, maternal literacy, socioeconomic level, and household family size were significantly associated with under-5 mortality $(\mathrm{P}<0.05)$. Moreover, there was a correlation between a congenital defect in the Zahak region and immaturity in the Hamun region with under-5 mortality.

Conclusion: Low socioeconomic status, parental addiction, and low education level were the most probable risk factors for under 5 mortality.
\end{abstract}

Keywords: Socioeconomic status, Under-5 mortality, Risk factor, Zabol

Conflicts of Interest: None declared

Funding: Deputy of Research, Shahid Beheshti University of Medical Sciences

*This work has been published under CC BY-NC-SA 1.0 license.

Copyright $\subseteq$ Iran University of Medical Sciences

Cite this article as: Nakhzari-Moghaddam M, Yavari P, Abadi A, Rostami-Gooran N. Association of socioeconomic risk factors with under 5-year mortality in Zabol, Iran, during 2011-2015. Med J Islam Repub Iran. 2019 (26 Jun);33:61. https://doi.org/10.47176/mjiri.33.61

\section{Introduction}

Under 5 mortality is an important indicator of a country's development and there is a global commitment to reduce its rate (1). The movement towards health equity by focusing on socioeconomic factors is emphasized in the Human Rights Declaration (2). Decreasing the health gap is a strategic and valuable goal of governments. Also, increasing social standards among low socioeconomic levels and eliminating inequality is a goal of World Health Organization

\section{Corresponding author: Dr Parvin Yavari, p.yavari-grc@sbmu.ac.ir}

1. Faculty of Medicine, Zabol University of Medical Sciences; Zabol, Iran

2. Social Determinants of Health Research Center, Shahid Beheshti University of Medical Sciences, Tehran, Iran

3. Department of Community Medicine, Faculty of medicine, Shahid Beheshti University of Medical Sciences, Tehran, Iran

4. Ministry of Health and Medical Education, Tehran, Iran
(WHO) and obtaining reliable information about the etiology of mortality is an important step to develop health plans and allocate the $r$ elated budget $(3,4)$.

In recent decades, 2 approaches have been defined for health: (1) the medical approach by technology and treatment, and (2) the approach which considers health as a social phenomenon. However, it is evident that without focusing on the social factors, one cannot improve health just

$\uparrow$ What is "already known" in this topic:

Children under 5 are vulnerable to the imbalance of socioeconomic inequality and are dependent on the adults to remain healthy. To eliminate the causes of inequality in health, the relationship between the social determinants and their effects on health should be determined.

$\rightarrow$ What this article adds:

Parental addiction and low education level were the most probable risk factors for under 5 mortality which need to be addressed in future regional plans to improve the health of children. 
by medical approaches (5).

Children under 5 years are vulnerable to the effects of social and financial inequality and depend on their adults to guarantee their health (6). To eliminate the causes that create inequality in health, the relationship between the social determinants and their effect on health should be determined (7).

In 2010, WHO categorized social determinants of health to macro politics, socioeconomic status, education, sex, social and cultural values, behavioral and psychological causes, and the health system (2). In a study by Haghdoost et al, on the health indicators based on the health statistics of the rural areas in 2005, under 5 mortality rate in Sistan \& Baluchestan villages was 35 in 1000 live births, which was placed last in the national ranking, while Tehran with an under 5 mortality rate of 14 in 1000 had the best position (8). Rafiee et al performed a study on under 5 mortality in 31 provinces of Iran and compared its changes within 5 years using the data from 2006 to 2011 (9). They showed that Sistan \& Baluchestan and Tehran had the highest and lowest under 5 mortality rate in 2011, respectively. Also, Sistan \& Baloochestan is a deprived province in Iran and suffers from inequality of in-patient health care (10).

Thus, to find solutions for the Sistan \& Baluchestan province, in this study, it was aimed to determine the causes of under 5 mortality and its associated social determinants in Zabol.

\section{Methods}

In this descriptive cross sectional study, all dead and alive cases of children under 5 years in Zabol, Sistan \& Baluchestan province, Iran, were included during 2011-2016. For the deceased children, date of birth, sex, and place of residence were recorded based on the health center vaccination files and the data on the age at death, cause of death, and mother's age and education were obtained using standard questionnaires of the Ministry of Health. For alive children, data on sex, age, mother's age, and family size were obtained using the files in health centers. To categorize family's socioeconomic status, ethnicity, faith, parental education, and drug abuse, all families were interviewed using questionnaires. Cases were considered positive for drug abuse if the family used drugs before the child's death. Socioeconomic status was categorized by scoring the social variables using a standardized questionnaire ${ }^{11}$. Also, the variables in this questionnaire included parental education, living condition, owning a private car, and personal computer, which were obtained by the questionnaires. The maximum score in this questionnaire was 48 , and socioeconomic status was divided into 4 categories of weak, moderate, good, and excellent status.

Living places were divided into 5 regions: Hirmand, Hamun, Nimruz, Zahak, and Zabol. Living situation was categorized as rural, urban, and nomadic. The ethnicity categories included non-native, Sistani, and Baluch. For religion, 2 major Muslim faiths, Shiite and Sunnite were considered. Parents' education level was divided into illiterate, primary school, secondary school, and university degree.

\section{Statistical analysis}

Categorical variables were described through frequency and percentage and were compared among the above-mentioned groups using chi-squared test. The continuous variables were expressed as mean and standard deviation using t test. Univariable and multivariable logistic regression was used to determine the final associated factors. $\mathrm{P}<0.05$ was considered as statistically significant. The statistical analyses were performed using SPSS Statistics for Windows, version 21.0 (Armonk, NY: IBM Corp.).

\section{Results}

A total of 667 dead and 1334 alive children younger than 5 were identified in the study region during 2011-2016. Dead children included 351 (52.6\%) boys and $316(47.4 \%)$ girls. Most of the dead children were younger than 1 month (366 deaths [54.9\%]), while $207(31.0 \%)$ cases were from 1 month to 1 -year-old and $94(14.1 \%)$ cases were 1 to 5 years old. Moreover, 38 (5.8\%) families of the dead chil-

Table 1. Distribution of causes of under-five mortality based on the age groups in Zabol (2011-2015)

\begin{tabular}{|c|c|c|c|c|c|}
\hline Age Under 5 & & & Under 1 month & & \\
\hline Cause of death & Number & Percent & Cause of death & Number & Percent \\
\hline Immaturity & 173 & 25.9 & Immaturity & 168 & $49.90 \%$ \\
\hline Congenital defect & 87 & $13 \%$ & Respiratory & 43 & $11.70 \%$ \\
\hline Respiratory & 76 & $11.40 \%$ & Congenital & 42 & $11.50 \%$ \\
\hline Accident & 70 & $9.50 \%$ & Unknown & 23 & $6.40 \%$ \\
\hline Central nervous system & 46 & $6.90 \%$ & Birth origin & 17 & $4.60 \%$ \\
\hline Cardiac & 44 & $6.60 \%$ & Cardiac & 14 & $3.80 \%$ \\
\hline Infectious & 35 & $5.20 \%$ & Infectious & 13 & $3.60 \%$ \\
\hline Unknown & 34 & $5.10 \%$ & Other causes & 12 & $3.30 \%$ \\
\hline Gastrointestinal & 32 & $4.80 \%$ & Central nervous system & 9 & $2.50 \%$ \\
\hline Birth origin & 17 & $2.50 \%$ & Accident & 8 & $2.10 \%$ \\
\hline Other causes & 14 & $2.10 \%$ & Gastrointestinal & 6 & $1.60 \%$ \\
\hline Cancer & 12 & $1.80 \%$ & Sudden death & 4 & $1.10 \%$ \\
\hline Blood & 8 & $1.20 \%$ & Kidney and urinary tract & 4 & $1.10 \%$ \\
\hline Kidneys and urinary tract & 6 & $0.90 \%$ & Blood & 3 & $0.80 \%$ \\
\hline Sudden death & 5 & $0.70 \%$ & Total & 366 & $100 \%$ \\
\hline Metabolic & 3 & $0.40 \%$ & & & \\
\hline Growth retardation & 2 & & & & \\
\hline Psychological & 2 & & & & \\
\hline Immune system & 1 & & & & \\
\hline Total & 667 & & & & \\
\hline
\end{tabular}




\begin{tabular}{|c|c|c|c|c|c|}
\hline \multirow{2}{*}{$\begin{array}{l}\text { One month to } 1 \text { year } \\
\text { Cause of death }\end{array}$} & \multicolumn{5}{|c|}{ One to 5 years } \\
\hline & Number & Percent & Cause of death & Number & Percent \\
\hline Congenital & 37 & $17.90 \%$ & Accidents & 41 & $43.60 \%$ \\
\hline Respiratory & 31 & $15 \%$ & Central nervous system & 13 & $13.80 \%$ \\
\hline Cardiac & 24 & $11.60 \%$ & Congenital & 8 & $8.50 \%$ \\
\hline Central nervous system & 24 & $11.60 \%$ & Cardiac & 6 & $6.40 \%$ \\
\hline Gastrointestinal & 19 & $9.20 \%$ & Infectious & 6 & $6.40 \%$ \\
\hline Infectious & 16 & $7.70 \%$ & Gastrointestinal & 7 & $7.40 \%$ \\
\hline Accident & 21 & $10.1 \%$ & Cancer & 5 & $5.30 \%$ \\
\hline Unknown & 10 & $4.80 \%$ & Metabolic & 2 & $2.10 \%$ \\
\hline Cancer & 7 & $3.40 \%$ & Respiratory & 2 & $2.10 \%$ \\
\hline \multirow{2}{*}{ Immaturity } & 5 & $2.40 \%$ & Unknown & 1 & $1.10 \%$ \\
\hline & & $2.90 \%$ & Psychological & 1 & $1.10 \%$ \\
\hline Blood & 5 & $2.40 \%$ & Kidney and urinary tract & 1 & $1.10 \%$ \\
\hline Other causes & 2 & $1 \%$ & Growth decline & 1 & $1.10 \%$ \\
\hline Kidney and urinary tract & 1 & $0.50 \%$ & Total & 94 & $100 \%$ \\
\hline Sudden death & 1 & $0.50 \%$ & & & \\
\hline Metabolic & 1 & $0.50 \%$ & & & \\
\hline Growth decline & 1 & $0.50 \%$ & & & \\
\hline Psychological & 1 & $0.50 \%$ & & & \\
\hline Immune system & 1 & $0.50 \%$ & & & \\
\hline Total & 207 & $100 \%$ & & & \\
\hline
\end{tabular}

dren could not be reached for the completion of the questionnaires, so their available data in the health care system were used.

The common cause of under 5 mortality was immaturity in $173(25.9 \%)$, congenital defects in $87(13 \%)$, and respiratory diseases in $76(11.4 \%)$ children. The most important cause of mortality in under 1 month of age was immaturity $(49.9 \%)$ and in 1 month to 1 year was congenital anomaly $(17.9 \%)$, and in 1 to 5 years was accident $(43.6 \%)$ (Table 1).

In contingency table and chi-squared test, the frequency of death due to congenital defects was significantly higher in Zahak region (33 cases [17.6\%], with an overall average of $11.2 \%$ ), while the frequency of death due to immaturity was higher in Hamun region (30 cases [40.5\%], with an overall average of $24.1 \%)$. A total of $132(19.8 \%)$ children were living in urban areas and $535(80.2 \%)$ in the rural areas.

Based on the results of the $t$ test, the mean age of the mothers was $27.9 \pm 6.4$ years in dead cases and $28.7 \pm 6.1$ years in alive children $(\mathrm{p}=0.009)$.

Based on the univariable logistic regression model, there was a significant association between mother and father's smoking, addiction, education level, mother's age, socioeconomic status, and family size with under 5 mortality (Table 2).

In the multivariable logistic regression model, father's addiction, maternal literacy, socioeconomic level, and household family were significantly associated with under 5 mortality. The estimated odds ratio for under 5 year mortality was 2.6 among addicted fathers compared to nonaddicted fathers $(p=0.01)$. Also, the estimated odds ratio for

\begin{tabular}{|c|c|c|c|c|c|c|}
\hline Characteristics & $\begin{array}{l}\text { Group of dead chil- } \\
\text { dren }\end{array}$ & $\begin{array}{l}\text { Group of alive chil- } \\
\text { dren }\end{array}$ & OR & CI 95\% & & $\mathrm{p}$ \\
\hline & Number (percent) & Number (percent) & & $\begin{array}{l}\text { Lower } \\
\text { limit }\end{array}$ & $\begin{array}{l}\text { Upper } \\
\text { limit }\end{array}$ & \\
\hline Mother's smoking (Hookah) & $13(2)$ & $12(0.9)$ & 2.3 & 1.05 & 5 & 0.03 \\
\hline Father's smoking (Hookah and cigarette) & $32(5.1)$ & $28(2.1)$ & 2.5 & 1.4 & 4.1 & $<0.001$ \\
\hline Mother's addiction & $20(3.2)$ & $4(0.3)$ & $\begin{array}{c}10 . \\
9\end{array}$ & 3.7 & 32 & $<0.001$ \\
\hline Father's addiction & $35(5.6)$ & $12(0.9)$ & 6.4 & 3.3 & 12.5 & $<0.001$ \\
\hline Father's education (illiterate and primary) & $237(37.7)$ & $179(13.4)$ & 3.9 & 3.1 & 4.8 & $<0.001$ \\
\hline $\begin{array}{l}\text { Mother's education (illiterate and pri- } \\
\text { mary) }\end{array}$ & $332(52.8)$ & $291(21.8)$ & 4 & 3.2 & 4.9 & $<0.001$ \\
\hline First social financial level & $351(55.8)$ & $156(11.7)$ & 9.5 & 7.5 & 11.9 & $<0.001$ \\
\hline Family population under 5 people & $546(86.8)$ & $1094(82)$ & 1.4 & 1.1 & 1.8 & 0.007 \\
\hline Mother's age, year & 27.9 & 28.7 & & & & 0.009 \\
\hline \multicolumn{7}{|l|}{ Child's sex } \\
\hline Boy & $351(52.6)$ & $661(49.6)$ & 0.8 & 0.7 & 1.06 & 0.1 \\
\hline Girl & $316(47.4)$ & $673(50.4)$ & & & & \\
\hline \multicolumn{7}{|l|}{ Faith } \\
\hline Shiite & $367(58.3)$ & $789(59.1)$ & 0.9 & 0.7 & 1.1 & 0.6 \\
\hline Sunnite & $262(41.7)$ & $545(40.9)$ & & & & \\
\hline \multicolumn{7}{|l|}{ Ethnicity } \\
\hline Sistani & $365(58)$ & $788(59)$ & 0.9 & 0.7 & 1.1 & 0.6 \\
\hline Baluch & $262(41.7)$ & 545 (40.9) & $\begin{array}{c}1.0 \\
3\end{array}$ & 0.8 & 1.1 & 0.7 \\
\hline Not local & $2(0.3)$ & $1(0.1)$ & 4.2 & 0.3 & 4.2 & 0.2 \\
\hline
\end{tabular}




\begin{tabular}{|c|c|c|c|c|}
\hline Characteristics & OR & CI $95 \%$ for $\mathrm{OR}$ & & $\mathrm{p}$ \\
\hline & & Lower limit & Upper limit & \\
\hline Mother's addiction & 2.9 & 0.8 & 10.5 & 0.09 \\
\hline Father's addiction & 2.6 & 1.1 & 5.7 & 0.01 \\
\hline Father's smoking & 1.8 & 0.8 & 4.05 & 0.1 \\
\hline Mother's smoking & 1.02 & 0.3 & 2.6 & 0.9 \\
\hline Father level of education (illiterate/primary) & 1.2 & 0.8 & 1.7 & 0.2 \\
\hline Mother level of education (illiterate/primary) & 2.2 & 1.6 & 2.9 & $<0.001$ \\
\hline Low socioeconomic level & 7.8 & 5.8 & 10.4 & $<0.001$ \\
\hline Family size $<5$ & 2.6 & 1.8 & 3.7 & $<0.001$ \\
\hline
\end{tabular}

under 5 mortality was 2.2 among illiterate mothers compared to mothers with primary education $(\mathrm{p}<0.001)$. The estimated odds ratio for under 5 mortalities was 7.8 in those with low socioeconomic level compared to others $(\mathrm{p}<0.0001)$. The estimated odds ratio for under 5 mortalities was 2.6 in family size $<5$ compared to family size $>5$ $(\mathrm{p}<0.001)$ (Table 3).

\section{Discussion}

Based on the findings of this study, the most common causes of under 5 mortality were immaturity, congenital defects, and respiratory diseases, respectively. The most common cause of death in under 1 year-olds was immaturity and for 1 to 5 year-olds was accident, which was similar to Barak's study in Ardabil in 2010 (12). Similarly, Sharifzadeh et al study in Birjand showed that the most common cause of death among under 5 children were immaturity $(44 \%)$ and congenital defects $(15 \%)(13)$. The results of the above-mentioned studies and those of the present study were similar to the global common causes of death in children as shown by Liu et al in 2013 in which immaturity was the most common cause of death in children younger than 5 years $^{13}$. In the present study, there were 12 deaths due to choking under breast in under 5 year-old children, which is noteworthy, and it was only reported in 1 study by Shahraki et al in 2007 (14) (3 cases [3.3\%]).

In this study, children's sex was not a significant factor. However, Damghanian et al in Shahrud (2011) reported a higher death rate among boys (1.6 times more than girls) (15). Hosseinpoor et al study in 2000 showed a 1.1 folds higher risk of death in male children (16). A review article in 2013 showed that being male is a risk factor for under 5 mortality ${ }^{17}$. However, in Tajdini et al study (2012), which discussed under 5 mortality (1), the frequency of death among boys and girls were statistically similar. Although there was no statistically significant difference between the death of girls and boys, the frequency of death was slightly higher in boys.

Maternal drug abuse was an important associated factor in the present study as well as paternal drug abuse, which was more associated with immaturity and respiratory diseases. This is in line with Sharifzadeh et al study in which maternal drug abuse had an odds ratio of 4 (13). Additionally, Torshizi et al study in Birjand in 2007 showed that maternal drug abuse was associated with a higher rate of child mortality (18). The abused drug used in all the abovementioned studies was opioid. In a 10 -year study by Vucinovic in Ukraine (19), the prevalence of maternal drug abuse was $0.2 \%$ and the most abused drug was heroin $(50 \%)$, with an odds ratio of 11 for infant mortality. In
Wolfe et al study in California (2005), the maternal opioid abuse had an odds ratio of 1.2 for infant mortality, and the odds ratio for mortality after infancy was 3.8 (20).

In the present study, parental addiction had a significant role in under 5 mortality. Barak et al study showed that paternal cigarette smoking had an odds ratio of 3 for under 1 mortality (12). In a review article, maternal smoking was significantly associated with infant mortality (17). Banderali et al also found a significant association between maternal smoking and infant death (21). In Minnes et al study (22), a significant association was found between parental addiction and infant death.

In the present study, the lowest socioeconomic level was associated with a higher frequency of under 5 mortality. Similar findings were also observed in Hosseinpoor et al (16) and Damghanian et al (15) studies. In a study by Alison et al (23), the lowest socioeconomic level had the odds ratios of 1.5 and 2.3 for infant mortality and after infancy mortality, respectively.

In the present study, low parental education level (illiterate and primary school level) was significantly associated with under 5 mortality. This was also in line with Mohammad et al study in 2011 in Bangladesh in which illiterate mothers, compared with mothers with higher education, had a higher risk of having a dead child (24). Also, it has been shown that maternal intermediate education, compared to primary education, had a protective role against infant mortality (15). Some other studies also showed that higher maternal education had a protective effect against child mortality $(12,13,17)$. Less emphasis has been put on father's education level and its effect on child mortality in the available studies. However, it should be noted that fathers' education and their health literacy can seriously affect the socioeconomic status of a family and thereby the health of the family members, particularly the children.

In this study, lower maternal age was significantly associated with child mortality, although this association was not present in the age subgroups. Maternal age under 20 years was associated with an increase in infant death in one study (13) while maternal age under 18 years was a risk factor in another study (25). In a study in Bangladesh, maternal age under 20 increased infant mortality (24).

Ethnicity was not a significant risk factor for under 5 mortality in the present study, which was similar to Nouri et al study (26).

Also, faith was not associated with under 5 mortality. Results of this study are different from those of Verona et al study (27) in Brazil and Guillot et al study (28) in India, both of which showed that religion and faith could impact child mortality. However, Shiite and Sunnite are both 
branches of Islam and there are many similarities between them.

In the present study, a family size of 3-4 was significantly associated with higher under 5 mortality than the family size of more than 4. A similar study in Bangladesh showed that larger family size ( $>4$ members) was a protective factor against infant mortality (odds ratio $=0.6$ ) (29). Nevertheless, Solomon et al study in Ethiopia showed that a larger family size was associated with an increase in infant and child mortality (30).

The strengths of this study were its 5-year duration and evaluating socioeconomic status using a questionnaire based on personal properties. Also, in this study, native expert health workers were employed to collect data and conduct interviews.

The most important shortcoming of the present study was the limitation in reaching and accessing all the families due to immigration and change of address. Second, as smoking and drug abuse are taboo in Iran, it is possible that the frequency of these conditions was underestimated, particularly in women. Although the data of the study were collected by native health workers, it is presumed that some people might have not trust them, and therefore had not provided them with honest answers.

\section{Conclusion}

Considering the findings of this study, common associated factors with under 5 mortality were immaturity, congenital defects, and respiratory diseases. Various factors, such as low socioeconomic status, parental addiction, and low education level were the most probable risk factors for under 5 mortality, which need to be addressed in future national and regional plans to improve the health of children. The results of this study can help the decisionmakers to determine the most useful interventions to reduce child mortality in this region.

\section{Acknowledgments}

This study was supported by Shahid Beheshti University of Medical Sciences, Tehran, Iran. The authors sincerely thank all participants for their kind contributions to this project and the staff of Zabol University of Medical Sciences who helped in data collection.

This study was supported by the Deputy of Research, Shahid Beheshti University of Medical Sciences, Tehran, Iran. (IR.SBMU.RETECH.REC.1395.669).

\section{Conflict of Interests}

The authors declare that they have no competing interests.

\section{References}

1. Tajedini F, Ehdaievand F, Farsar A. Epidemiological features of children mortality in the area covered by Shahid Beheshti university of medical sciences in 2012. J Clin Nurs Midwif. 2014;3(1):62-71.

2.Zaboli R, Malmoon Z, Seyedjavadi M, Seyedin H. Developing a conceptual model of social determinants of health inequalities: A qualitative study. J Health Prom Manag. 2014;3(4):74-88.

3. Wagstaff A. Socioeconomic inequalities in child mortality: comparisons across nine developing countries. Bull World Health Organ. 2000;78(1):19-29.
4. Khosravi A, Taylor R, Naghavi M, Lopez AD. Mortality in the islamic republic of Iran, 1964-2004 Bull World Health Organ. 2007;85(8):60714.

5. Anderko L. Achieving health equity on a global scale through a community-based, public health framework for action. J Law Med Ethics. 2010;38(3):486-9.

6. Blas E, Kurup AS. Equity, social determinants and public health programmes: World Health Organization; 2010.

7. AS R. Cultural context and a critical approach to eliminating health disparities. Ethnic Dis. 2010;20:71.

8. Rezaie F, Noori A, Haghdoost AA, Shokoohi M. The ecologic study of relationship between income and health indicators in iranian villages. Payesh. 2012;11(1):5-11.

9. Rafiei E, Hashemi Nazari SS, Mehrabi Y. Indirect Estimation of Infant and Child Mortality Rates in Iran: Using 2006 and 2011 Census Data. J Mazandaran Uni Med Sci. 2015;24(122):32-43.

10. Etemad K, Yavari P, Mehrabi Y, Haghdoost A, Motlagh ME, Kabir $\mathrm{MJ}$, et al. Inequality in utilization of in-patients health services in Iran. IJPM. 2015;6.

11. Garmaroudi GR, Moradi A. Socio-economic status in Iran: a study of measurement index. Payesh. 2010;9(2):137-44.

12. Barak M, Sadeghieh Ahari S, Amani F, Asadi G, Rahimi G, Khadem E. Causatives and Risk Factors for Deaths among Infants Under 1 Year Old in Ardabil Slums during 2008-2009. J Ardabil Uni Med Sci. 2012;12(5):40-7.

13. Sharifzadeh GR, Namakin K, Mehrjoofard H. An Epidemiological study on Infant Mortality and factors affecting it in Rural Areas of Birjand, Iran. Iran J Pediatr. 2008;18(4):335-42.

14. Shahraki VA, Mardani HM, Arab M, Firouzkouhi Z. Infant under 159 month mortality causes in Zabol. Iran J Nurs Midwifery Res. 2010;5(17):6-13.

15. Damghanian M, Shariati M, Mirzaiinajmabadi K, Yunesian M, Emamian MH. Socioeconomic inequality and its determinants regarding infant mortality in Iran. Iran Red Crescent Med 1. 2014;16(6).

16. Hosseinpoor AR, Van Doorslaer E, Speybroeck N, Naghavi M, Mohammad K, Majdzadeh R, et al. Decomposing socioeconomic inequality in infant mortality in Iran. Int J Epidemiol. 2006;35(5):1211-

17. Kim D, Saada A. The social determinants of infant mortality and birth outcomes in Western developed nations: a cross-country systematic review. Int J Environ Res Public Health. 2013;10(6):2296-335.

18. Torshizi M, Saadatjoo S, Farabi M. Prevalence of narcotic substance abuse and the maternal and fetal outcomes in pregnant women. Journal of Jahrom University of Medical Sciences. 2011;9(3):14-9.

19. Vucinovic M, Roje D, Vučnović Z, Capkun V, Bucat M, Banović I. Maternal and neonatal effects of substance abuse during pregnancy: our ten-year experience. Yonsei Med J. 2008;49(5):705-13.

20. Wolfe EL, Davis T, Guydish J, Delucchi KL. Mortality risk associated with perinatal drug and alcohol use in California. J Perinatoy. 2005;25(2):93-100.

21. Banderali G, Martelli A, Landi M, Moretti F, Betti F, Radaelli G, et al. Short and long term health effects of parental tobacco smoking during pregnancy and lactation: a descriptive review. J Transl Med. 2015;13(1):327.

22. Minnes S, Lang A, Singer L. Prenatal tobacco, marijuana, stimulant, and opiate exposure: outcomes and practice implications. Addict Sci Clin Pract . 2011;6(1):57.

23. Weightman AL, Morgan HE, Shepherd MA, Kitcher H, Roberts C, Dunstan FD. Social inequality and infant health in the UK: systematic review and meta-analyses. BMJ Open. 2012;2(3):e000964.

24. Mohammad KA, Bari W. Fine and Gray competing risk regression model to study the cause-specific under-five child mortality in Bangladesh. BMC Int Health Hum Rights. 2017;17(1):3.

25. Mohseni R, Pakzad H. Effect of sociol-economical conditions on mortality rate of under 5 years children, Khuzestan-Iran (2009). J Gorgan Uni Med Sci. Jorjani Biomed J. 2012;14(3).

26. Nouri A, Barati L, Qhezelsofly F, Niazi S. Causes of infant mortality in Kalaleh City during 2004-2012. 2013;1(2):32-37.

27. Verona APdA, Hummer R, Dias Júnior CS, Lima LCd. Infant mortality and mothers' religious involvement in Brazil. Rev Bras Estud Popu. 2010;27(1):59-74.

28. Guillot M, Allendorf K. Hindu-Muslim differentials in child mortality in India. Genus. 2010;66(2)

29. Uddin J, Hossain Z. Predictors of infant mortality in a developing 
Under-5 mortality rate in Zabol, Iran

country. Asian J Epidemiol. 2008;1(1):1-16

30. Gebretsadik S, Gabreyohannes E. Determinants of Under-Five Mortality in High Mortality Regions of Ethiopia: An Analysis of the 2011 Ethiopia Demographic and Health Survey Data. Int J Popul Re. $2016 ; 2016$ 